\title{
Cages versus Prisms: Controlling the Formation of Metallosupramolecular Architectures with Ligand Side-Chains
}

\author{
Giacomo Cecot, ${ }^{[a]}$ Martin Tim Doll, ${ }^{[a]}$ Ophélie Marie Planes, ${ }^{[a]}$ Andrea Ramorini, ${ }^{\left[{ }^{[a]}\right.}$ Rosario Scopelliti, ${ }^{[a]}$ \\ Farzaneh Fadaei-Tirani, ${ }^{[a]}$ and Kay Severin*[a]
}

\begin{abstract}
Metallosupramolecular assemblies of the general formula $\mathrm{M}_{2 n} \mathrm{~L}_{n}$ can adopt prismatic or cage-like structures. The factors controlling the aggregation number $n$ and the geometry of the final assembly are still not fully understood. Here, we describe the synthesis and the structural characterization of $\mathrm{Pt}_{8}{ }_{8} \mathrm{~L}_{4}$ complexes, which adopt tetragonal prismatic structures. The bridging ligand $\mathrm{L}$ features four pyridyl groups and an inert Fe" clathrochelate complex at its core. Furthermore, the ligand has three phenanthrene groups,

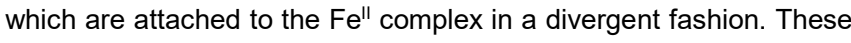
polyaromatic side groups control the self-assembly process by promoting the formation of a structure, which allows for an energetically favorable packing of the aromatic groups. Replacing the phenanthrene groups on the ligand by aliphatic $n$-butyl groups results in a complete change of geometry: instead of tetragonal prisms, $\mathrm{Pt}^{\prime \prime}{ }_{8} \mathrm{~L}_{4}$ complexes with cage-like structures are observed.
\end{abstract}

\section{Introduction}

Metallosupramolecular complexes with prismatic, barrel-like structures can be obtained by combining tetratopic $\mathrm{N}$-donor ligands with cis-blocked $\mathrm{Pd}^{\prime \prime}$ or $\mathrm{Pt}^{\prime \prime}$ complexes. ${ }^{[1-13]}$ The ligands panel the rectangular faces of the prisms, and the metal ions occupy the vertices (Figure 1, top). Complexes of this kind have the general formula $M_{2 n} L_{n}$. A first example of a trigonal prismatic $M_{6} L_{3}$ structure was described by Fujita and co-workers in 2001.[1] Since then, numerous other $M_{2 n} L_{n}$ prisms have been reported, and possible applications have been investigated. ${ }^{[2-13]}$ For example, $\mathrm{Pd}_{8} \mathrm{~L}_{4}$ barrels were shown to act as a carrier for fluorophores $^{9}$ and for curcumin, ${ }^{[11]}$ and to stabilize the merocyanine form of spiropyrans. ${ }^{[13]}$

Prismatic structures are not the only possible outcome for reactions of tetratopic $\mathrm{N}$-donor ligands with cis-blocked $\mathrm{Pd}^{\prime \prime}$ or $\mathrm{Pt}$ complexes. If the ligand can adopt a concave geometry, it is possible to form $\mathrm{M}_{4} \mathrm{~L}_{2}$-type structures. ${ }^{[14-22]}$ These complexes do not qualify as prisms, even though they can show a barrel-like geometry. An alternative structure for a complex of the formula $M_{12} L_{6}$ is a cube, with the ligands paneling all six faces. Such a

[a] Dr. G. Cecot, M. T. Doll, O. M. Planes, A. Ramorini, Dr. R. Scopelliti, Dr. F. Fadaei-Tirani, Prof. K. Severin

Institut des Sciences et Ingénierie Chimiques

École Polytechnique Fédérale de Lausanne (EPFL)

1015 Lausanne, Switzerland

Web.: http://lcs.epfl.ch

E-mail: kay.severin@epfl.ch

Supporting information for this article is given via a link at the end of the document. geometry was suggested for an assembly based on (en) $\mathrm{Pd}\left(\mathrm{NO}_{3}\right)_{2}$ (en = 1,2-ethylenediamine) and a tetrapyridyl ligand containing an organometallic Co complex. ${ }^{[22]}$ However, the analytical data do not exclude the formation of a hexagonal prismatic structure.

In 2016, we have shown that $\mathrm{M}_{8} \mathrm{~L}_{4}$-type complexes can not only form tetragonal prisms, but also cages with a gyrobifastigiumlike geometry (Figure 1, bottom). ${ }^{[23]}$ Subsequent studies by the group of Mukherjee led to the structural characterization of a $\mathrm{Pd}_{12} \mathrm{~L}_{6}$ cage with a triangular orthobicupola-like structure, ${ }^{[24]}$ and we have recently reported the structural characterization of a $\mathrm{Pt}_{16} \mathrm{~L}_{8}$ cage with a square orthobicupola-like structure. ${ }^{[25]}$

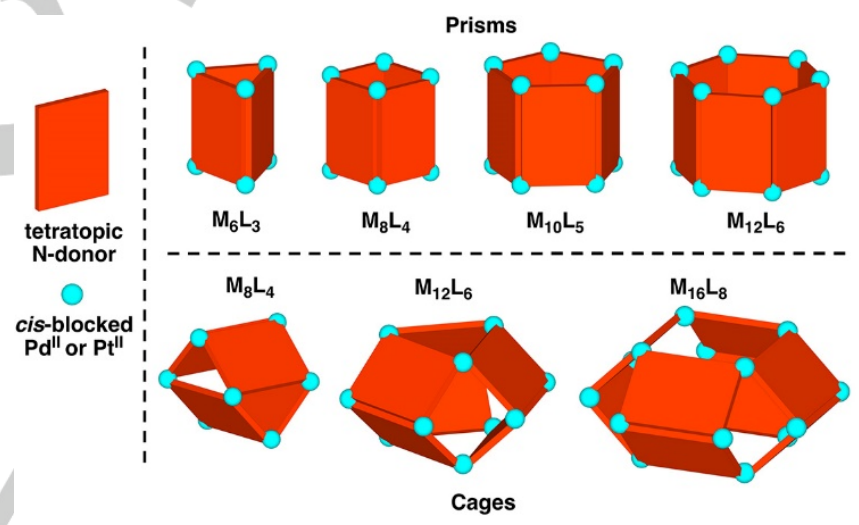

Figure 1. Geometries of metal-ligand assemblies based on tetratopic N-donor ligands and cis-blocked $\mathrm{Pd}^{\prime \prime}$ or $\mathrm{Pt}^{\prime \prime}$ complexes. Only crystallographically characterized complexes with prismatic or cage-like structures are taken into account.

The factors which control the assembly of $M_{2 n} L_{n}$-type structures are not fully understood. Overall, prismatic structures seem to be favored. ${ }^{[1-25]}$ Geometrical considerations suggest that the size of the prism is dependent on the relative orientation of the $\mathrm{N}$-donor groups. ${ }^{[25]}$ Geometrical factors are also of importance for the formation of cages (e.g. the distance between the $\mathrm{N}$-donor atoms), but other parameters are of relevance as well. For example, the self-assembly process can be influenced by the nature of the cis-blocked $\mathrm{M}^{11}$ complex. ${ }^{[25]}$ Furthermore, we have reasoned that the lateral size of a tetratopic $\mathrm{N}$-donor ligand is a significant factor for $M_{8} L_{4}$-type assemblies. ${ }^{[23,25,26]} \quad M_{8} L_{4}$ complexes can either form tetragonal prisms or gyrobifastigiumlike cages (Figure 1). In the cages, the ligand centers are further apart, and bulky ligands are thus expected to favor the formation of gyrobifastigium-like structures. In the following, we show that arguments based on steric bulk are too simplistic. In particular, 
we demonstrate that interactions between polyaromatic ligand side chains can be used to control the assembly of $M_{8} L_{4}$ complexes.

\section{Results and Discussion}

For our investigations, we have prepared the new metalloligand 1 (Scheme 1). This ligand contains an inert Fe" cage complex ('clathrochelate complex') ${ }^{[27,28]}$ in its center, and it features four terminal 4-pyridyl groups. The synthesis of 1 was accomplished in two steps. First, a tetrabrominated clathrochelate complex was prepared in a metal-templated condensation reaction between anhydrous $\mathrm{FeCl}_{2}$, phenanthrene-9,10-dione dioxime, ${ }^{[29]}$ and 3,5-dibromophenylboronic acid. Subsequent cross-coupling with 4-pyridylboronic acid gave ligand 1 in an overall yield of $48 \%$.

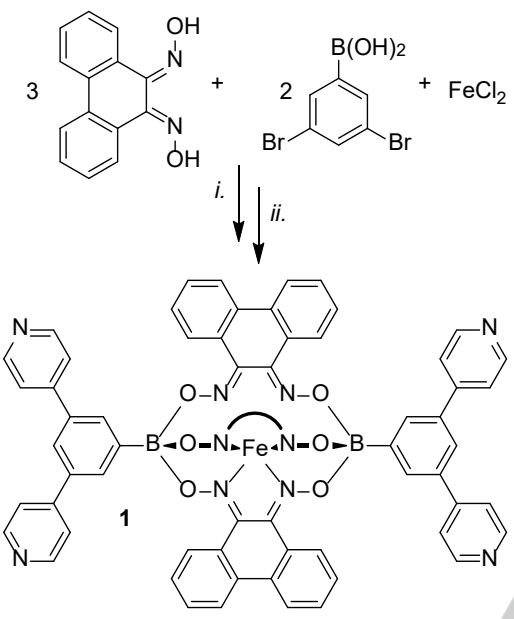

Scheme 1. Synthesis of metalloligand 1. Conditions: (i.) EtOH, reflux, $2 \mathrm{~d}$, yield: $88 \%$; (ii.) $n \mathrm{BuOH} /$ toluene (1:1), 4-pyridlyboronic acid (16 eq.), $\mathrm{Pd}_{2}(\mathrm{dba})_{3}(0.2 \mathrm{eq})$ SPhos (0.4 eq.), $\mathrm{K}_{3} \mathrm{PO}_{4}$ ( 8 eq.), $90{ }^{\circ} \mathrm{C}, 4$ d, yield: $55 \%$. a)

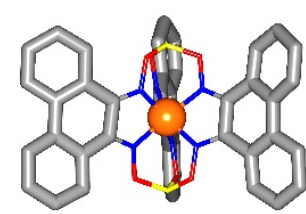

c)

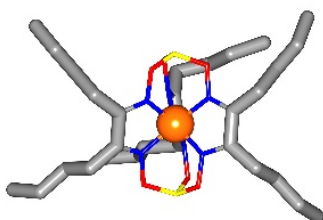

b)

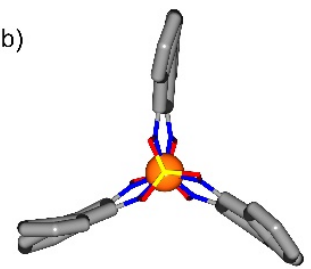

d)

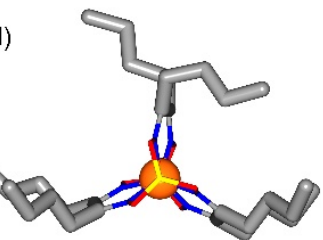

Figure 2. Molecular structures of the metalloligands 1 ( $a$ and b) and 2 (c and d) in the crystal, with view from the side and along the $\mathrm{B} \cdots \mathrm{B}$ axis. The terminal di(pyridyl-4-yl)phenyl groups are not shown for clarity. Color coding: C: gray, B: yellow, Fe: orange, N: blue, O: red.
Previously, we had used structurally related metalloligands such as 2 (Scheme 2) for the construction of metallosupramolecular assemblies. ${ }^{[25]} A$ unique feature of 1 is the presence of three bulky and rigid phenanthrene groups, which point away from the ligand center. Compared to other clathrochelate complexes described in the literature, ${ }^{[27,28]}$ the conformational flexibility of the central part of complex 1 is particularly low. The rigidity of the core of complex 1 is particularly evident when comparing its solid state structure (determined by $\mathrm{X}$-ray diffraction) with that of metalloligand $\mathbf{2}^{[25]}$ (Figure 2). Whereas a nearly perfect $C_{3}$-symmetrical structure is found for $\mathbf{1}$, the six flexible $n$-butyl chains of $\mathbf{2}$ do not adopt an ordered orientation.

Next, we have used the new metalloligand 1 for the synthesis of metal-ligand assemblies. As metal complexes, we have employed the cis-blocked $\mathrm{Pt}^{\prime \prime}$ complexes [(dppe)Pt(OTf $\left.)_{2}\right]$ and [(dppp)Pt $\left.(\mathrm{OTf})_{2}\right]$ (dppe = 1,2-bis(diphenylphosphino)ethane, dppp $=1,3$-bis(diphenylphosphino)propane). The reactions were performed in deuterated DMF, and equilibration of the systems was ensured by tempering the solutions at $50{ }^{\circ} \mathrm{C}$ for $12 \mathrm{~h}$ (Scheme 2, left side). The resulting solutions were then analyzed by NMR spectroscopy and mass spectrometry.

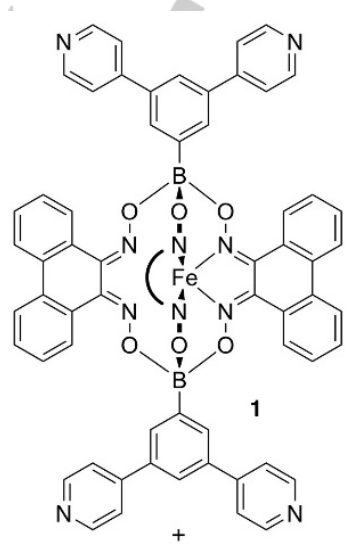

$2{ }_{\mathrm{Ph}^{-}}^{\mathrm{Ph}} \mathrm{X}_{\mathrm{Pt}} \mathrm{P}_{\mathrm{Ph}} \mathrm{Ph}$

( $n=2$ or 3) TfO' 'OTf

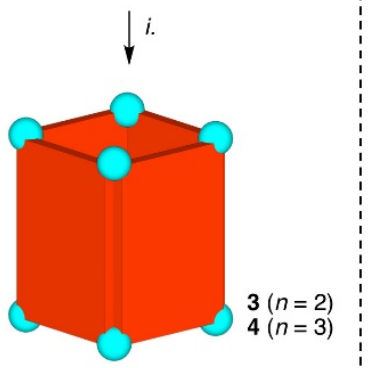<smiles>c1cc(-c2ccc(-c3ccncc3)cc2)ccn1</smiles><smiles>OB(O)O</smiles>

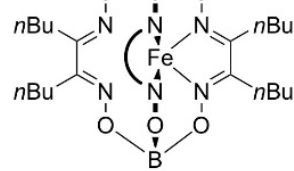<smiles>Cc1cc(-c2ccncc2)cc(-c2ccncc2)c1</smiles>

$2 \mathrm{Ph}^{\mathrm{Ph}} \mathrm{P}_{n} \mathrm{P}_{-\mathrm{Ph}} \mathrm{Ph}$ TfO' OTf $(n=2$ or 3$)$

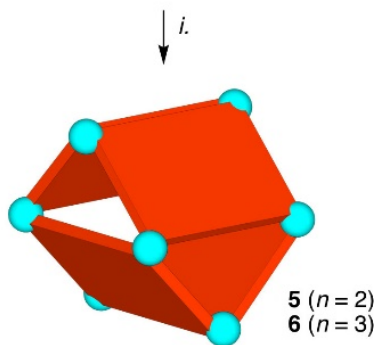

Scheme 2. Synthesis of the metal-ligand assemblies 3-6. Conditions: $(i$. DMF $-d_{7}, 50{ }^{\circ} \mathrm{C}, 12$ h, [Pt] 2 eq. ( $\left.0.6 \mathrm{mM}\right)$, [1] or [2] 1 eq. ( $\left.0.3 \mathrm{mM}\right)$.

The reactions between ligand 1 and $\left[(\mathrm{dppe}) \mathrm{Pt}(\mathrm{OTf})_{2}\right]$ gave rise to one major product with high symmetry (3), as indicated by a dominant singlet in the ${ }^{31} \mathrm{P}$ NMR spectrum (Figure 3b). By high resolution mass spectrometry, we were able to detect peaks which can be assigned to complexes of the general formula $\left[\{(\mathrm{dppe}) \mathrm{Pt}\}_{8}(\mathbf{1})_{4}(\mathrm{OTf})_{\mathrm{x}}\right]^{(16-\mathrm{x})+}$ (Figure 3a and Figure S16). Similar results were obtained for the reaction between 1 and 
[(dppp)Pt(OTf $)_{2}$ : the ${ }^{31} \mathrm{P}$ NMR spectrum showed one major singlet (Figure S8), and the MS data (Figure S22) indicated the formation of an assembly with the formula $\left[\mathrm{Pt}_{8}(\mathbf{1})_{4}\right]^{16+}(\mathbf{4})$.

We had previously investigated the reaction between ligand 2 and [(dppe)Pt(OTf $\left.)_{2}\right]$ and [(dppp)Pt(OTf $\left.)_{2}\right]$, and we had observed that the product in both cases was a cage structure with a gyrobifastigium-like geometry. ${ }^{[25]}$ These cages (5 and $\left.\mathbf{6}\right)$ show a characteristic feature in the ${ }^{31} \mathrm{P}$ NMR spectra, namely the presence of two singlets of equal intensity. The two signals are the result of two magnetically different $\mathrm{Pt}$ corners. To verify that solvent effects are not responsible for the differences between reactions with 1 and 2 , we have studied the assembly of the complexes 5 and 6 in DMF- $d_{7}$ (Scheme 2, right side). As for reactions in $\mathrm{CD}_{3} \mathrm{CN}$, we found that the dominant species in solution gave rise to two singlets of equal intensity (Figure $3 \mathrm{~d}$ and Figure S11 and S14), indicating the formation of a gyrobifastigium-like cage structure. The ${ }^{31} \mathrm{P}$ NMR spectra of the reactions with ligand $\mathbf{2}$ also showed a small singlet, suggesting that a low amount of a second species had formed during the assembly process.
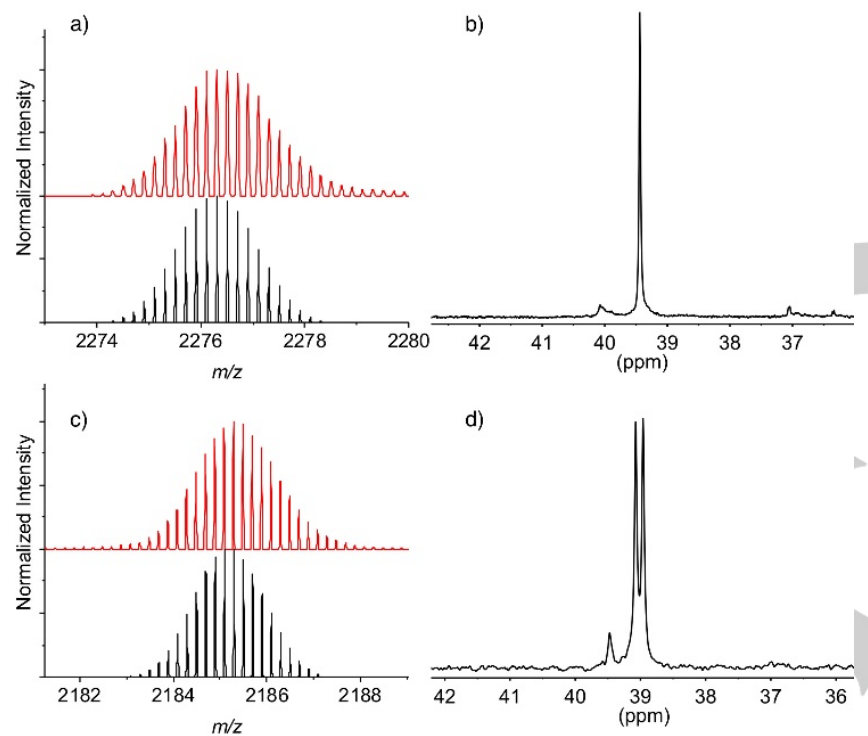

Figure 3. a) Part of the ESI MS spectrum of a solution containing ligand 1 and [(dppe)Pt(OTf $)_{2}$; the peak can be assigned to a species of the formula $\left[\{(\mathrm{dppe}) \mathrm{Pt}\}_{8}(\mathbf{1})_{4}(\mathrm{OTf})_{11}\right]^{5+}$ (red: exp.; black: theor.); b) ${ }^{31} \mathrm{P}$ NMR spectrum of the same reaction mixture; $c)$ Part of the ESI MS spectrum of a solution containing ligand 2 and [(dppe)Pt(OTf $)_{2}$; the peak can be assigned to a species of the formula $\left[\{(\mathrm{dppe}) \mathrm{Pt}\}_{8}(2)_{4}(\mathrm{OTf}){ }_{11}\right]^{5+}$ (red: exp.; black: theor.); d) ${ }^{31} \mathrm{P}$ NMR spectrum of the same reaction mixture. All spectra were acquired in DMF- $d_{7}$.

The analytical data showed that tetragonal prisms had formed in reactions with ligand $\mathbf{1}$, whereas cages had formed with ligand 2. The different outcome of the reactions must be related to the side chains of the central iron complex ( $n$-butyl vs. phenanthrene). We had reasoned previously that the lateral size of a ligand can be a decisive element for the assembly of $\mathrm{M}_{8} \mathrm{~L}_{4}$-type structures, and geometrical considerations suggest that wider ligands should favor cage-like structures over prisms. ${ }^{[23,25]}$ However, it is difficult to argue that the lateral size of ligand $\mathbf{2}$ is larger than that of ligand 1. On the contrary, the effective width of ligand 2 should be smaller due to the higher flexibility of the $n$-butyl side chains.
A crystallographic analysis gave valuable insight on assembly 4. In line with the analytical data, a prismatic $M_{8} L_{4}$ structure is observed (Figure 4). The height of the prism is $19.3 \AA$, and its width is $13.6 \AA$ (average Pt $\cdots$ Pt distances). The two smaller sides of the prism do not display a square geometry, but rather the shape of a rhombus. The arrangement of the lateral phenanthrene side chains is of special interest. Four of the 12 phenanthrene groups point to the inside of the prism, and completely fill the central part of the assembly (Figure S42). One can observe a very tight packing of the phenanthrene groups, with favorable $e^{[30,31]}$ parallel offset and T-shaped interactions between the polycyclic aromatic groups (Figure 4, bottom). The two phenanthrene group pointing to the center of the prism are essentially co-planar, with $\mathrm{C} \cdots \mathrm{C}$ distances as close as $3.32 \AA$. Regarding $\mathrm{C}-\mathrm{H}$ groups pointing towards adjacent $\pi$-systems, one can observe $\mathrm{CH} \cdots \mathrm{C}$ distances of down to $2.84 \AA$. The perfectly interdigitating phenanthrene groups in assembly $\mathbf{4}$ are likely the reason for the preferential formation of a prismatic instead of a cage-like structure.

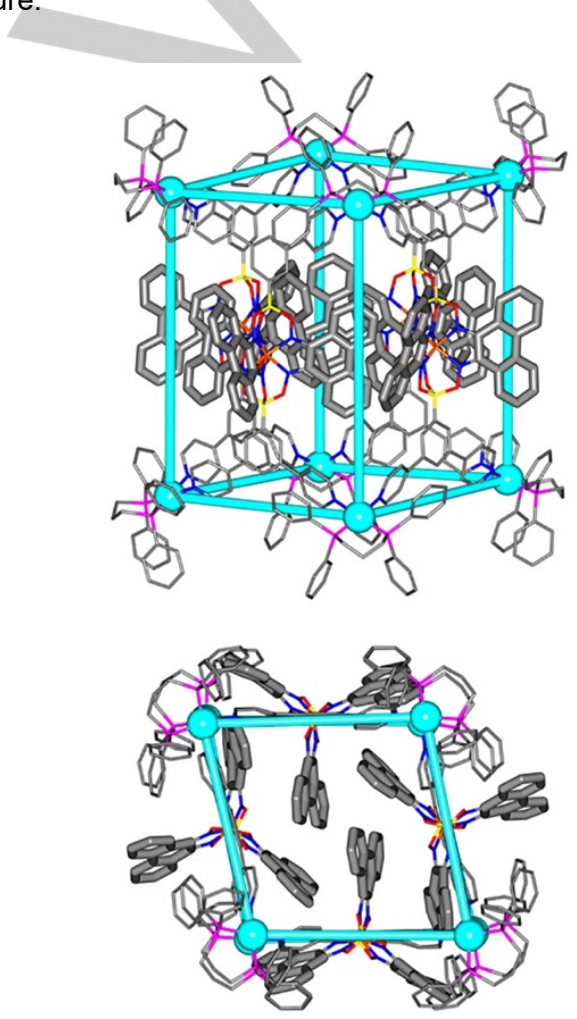

Figure 4. Molecular structure of complex 4 in the crystal with view from the side (top) and along the barrel axis (bottom). The overall geometry is indicated by (virtual) Pt-Pt bonds. Color coding: C: gray, B: yellow, Fe: orange, Pt: cyan, P: purple, N: blue, O: red. The hydrogen atoms, all counter ions, and solvent molecules are omitted for clarity.

\section{Conclusions}

Over the last two decades, several groups have investigated the synthesis and the properties of metallosupramolecular $\mathrm{M}_{2 n} \mathrm{~L}_{n}$ complexes. ${ }^{[1-25]}$ The common strategy for preparing these assemblies is to mix cis-blocked square planar metal complexes with tetratopic $\mathrm{N}$-donor ligands. With the recent isolation of cage structures instead of the commonly observed prismatic structures, 
it became apparent that the factors controlling the assembly of $\mathrm{M}_{2 n} \mathrm{~L}_{n}$ are not fully understood. In previous studies, we had identified some important parameters, such as the geometry of the ligand, the nature of the metal complex, and the overall width of the ligand. ${ }^{[23,25]}$ Here, we have shown that ligands with similar geometry and width can give completely different structures. A new tetrapyridyl ligand was prepared. An important feature of this ligand is the presence of three phenanthrene groups. These polyaromatic side groups control the self-assembly process by promoting the formation of tetragonal prismatic structures, which allow for an energetically favorable packing of the aromatic groups. When the phenanthrene groups are replaced by aliphatic $n$-butyl groups, cage-like structures are observed instead. Overall our results are further evidence for the importance of ligand-ligand interactions ${ }^{[32-40]}$ in metallosupramolecular chemistry.

\section{Experimental Section}

General: Diethyl glyoxime, ${ }^{[41]}$ phenanthrene-9,10-dione dioxime, ${ }^{[29]}$ and ligand $2^{[25]}$ were prepared as described in the literature. The complexes (dppe) $\mathrm{PtCl}_{2}$ and (dppe)Pt(OTf) $)_{2}$ were prepared in analogy to a published procedure. ${ }^{[42]}$

NMR spectra were obtained on a Bruker Avance III spectrometer $\left({ }^{1} \mathrm{H}: 400 \mathrm{MHz}\right)$ or a Bruker Avance III HD spectrometer $\left({ }^{1} \mathrm{H}\right.$ : $600 \mathrm{MHz}$ ). Spectra were recorded at $298 \mathrm{~K}$, and the chemical shifts are reported in parts per million $\delta(\mathrm{ppm})$ referenced to the residual solvent signal. ${ }^{31} \mathrm{P}$ spectra are referenced to an external standard $\left(\mathrm{H}_{3} \mathrm{PO}_{4} 85 \%\right)$. The analyses of the NMR spectra were performed with MestreNova. For the DOSY analysis, the Bayesian DOSY transform from MestreNova was employed.

High resolution mass spectra were obtained using a Xevo G2-S QTOF mass spectrometer coupled to the Acquity UPLC Class Binary Solvent manager and BTN sample manager (Waters, Corporation, Milford, MA), or a LTQ Orbitrap FTMS instrument (LTQ Orbitrap Elite FTMS, Thermo Scientific, Bremen, Germany) operated in the positive mode coupled with a robotic chip-based nano-ESI source (TriVersa Nanomate, Advion Biosciences, Ithaca, NY, U.S.A.). Additional information are given in the Supporting Information.

Synthesis of ligand 1: The syntheses of the intermediate clathrochelate complex (complex 'A') and of ligand 1 were performed under an atmosphere of nitrogen using standard Schlenk techniques with degassed solvents.

Complex A: EtOH $(15 \mathrm{~mL})$ was added to a mixture of phenanthrene-9,10-dione dioxime $(150 \mathrm{mg}, 630 \mu \mathrm{mol})$, 3,5-dibromophenylboronic acid (117mg, $420 \mu \mathrm{mol})$, and anhydrous $\mathrm{FeCl}_{2}(27 \mathrm{mg}, 213 \mu \mathrm{mol})$ leading to a purple suspension. The mixture was heated under reflux for 2 days and then it was allowed to cool to RT. The solvent was removed under reduced pressure, and the mixture was suspended in $\mathrm{MeOH}$ $(15 \mathrm{~mL})$. Complex $\mathbf{A}$ was isolated by filtration, washed with cold $\mathrm{MeOH}(3 \times 5 \mathrm{~mL}), \mathrm{Et}_{2} \mathrm{O}(3 \times 5 \mathrm{~mL})$, and pentane $(3 \times 5 \mathrm{~mL})$ to give a dark purple powder. Yield $88 \%$. ${ }^{1} \mathrm{H}$ NMR $\left(400 \mathrm{MHz}, \mathrm{CD}_{2} \mathrm{Cl}_{2}\right) \delta$ $9.67(\mathrm{~d}, J=8.2 \mathrm{~Hz}, 6 \mathrm{H}), 8.28(\mathrm{~d}, J=7.8 \mathrm{~Hz}, 6 \mathrm{H}), 8.24(\mathrm{~s}, 4 \mathrm{H})$, $7.84(\mathrm{~s}, 1 \mathrm{H}), 7.66-7.52(\mathrm{~m}, 12 \mathrm{H})$. Because of the poor solubility, a ${ }^{13} \mathrm{C}$ NMR spectrum was not recorded. HRMS-ESI: $\mathrm{m} / \mathrm{z}$ calculated for $\mathrm{C}_{54} \mathrm{H}_{30} \mathrm{~B}_{2} \mathrm{Br}_{4} \mathrm{FeN}_{6} \mathrm{O}_{6} \quad[\mathrm{M}+\mathrm{H}]^{+}$1252.8559, found 1252.8524.

Ligand 1: A mixture of $n \mathrm{BuOH}$ and toluene $(1: 1,20 \mathrm{~mL})$ was added to a mixture of complex A $(230 \mathrm{mg}, 183 \mu \mathrm{mol}), 4$ pyridylboronic acid $(412 \mathrm{mg}, 2.92 \mu \mathrm{mol}), \mathrm{Pd}_{2}(\mathrm{dba})_{3}(67 \mathrm{mg}$, $73 \mu \mathrm{mol}$ ), SPhos (60 mg, $146 \mu \mathrm{mol}$ ), and $\mathrm{K}_{3} \mathrm{PO}_{4}(311 \mathrm{mg}, 1.47$ $\mathrm{mmol})$. The mixture was stirred at $90{ }^{\circ} \mathrm{C}$ for 4 days and then it was allowed to cool to RT. The solvent was co-evaporated four times adding at each evaporation step toluene. The resulting dark red powder was dissolved in DCM and transferred into a separatory funnel. The organic layer was washed with a solution of saturated $\mathrm{NaHCO}_{3}, \mathrm{H}_{2} \mathrm{O}$ and dried over $\mathrm{MgSO}_{4}$. After filtration, the solvent was removed under reduced pressure leading to a purple powder. The product was purified by column chromatography $\left(\mathrm{SiO}_{2} 230\right.$ 400 mesh) DCM/MeOH 92:8. The fractions containing the product were collected, and the solvent was removed under reduced pressure. Yield 55\%. ${ }^{1} \mathrm{H}$ NMR $\left(400 \mathrm{MHz}, \mathrm{CD}_{2} \mathrm{Cl}_{2}\right) \delta 9.83$ (dd, $J=$ $8.4,1.3 \mathrm{~Hz}, 6 \mathrm{H}), 8.76(\mathrm{~d}, J=6.2 \mathrm{~Hz}, 8 \mathrm{H}), 8.61(\mathrm{~d}, J=1.9 \mathrm{~Hz}, 4 \mathrm{H})$, $8.35(\mathrm{~d}, J=8.1 \mathrm{~Hz}, 6 \mathrm{H}), 8.16(\mathrm{~s}, 2 \mathrm{H}), 7.83(\mathrm{~d}, J=6.1 \mathrm{~Hz}, 8 \mathrm{H})$, $7.65(\mathrm{t}, J=7.7 \mathrm{~Hz}, 6 \mathrm{H}), 7.51(\mathrm{t}, J=8.0 \mathrm{~Hz}, 6 \mathrm{H}) .{ }^{13} \mathrm{C}$ NMR $\left(151 \mathrm{MHz}, \mathrm{CD}_{2} \mathrm{Cl}_{2}\right) \delta 150.98,149.07,148.46,139.14,132.91$, 132.07, 131.81, 131.03, 129.28, 126.12, 124.90, 124.37, 122.30 (C-B carbon was not detected). HRMS-ESI $\mathrm{m} / \mathrm{z}$ calculated for $\mathrm{C}_{68} \mathrm{H}_{40} \mathrm{~B}_{2} \mathrm{FeN}_{10} \mathrm{O}_{6}[\mathrm{M}+\mathrm{H}]^{+}$1171.2740, found 1171.2769; $[\mathrm{M}+2 \mathrm{H}]^{2+}$ 586.1406, found 586.1424 .

Syntheses of the assemblies 3-6: The ligand (1 eq.) and the respective Pt complex (2 eq.) were suspended in deuterated DMF $(0.5 \mathrm{~mL})$. The mixtures were heated at $50{ }^{\circ} \mathrm{C}$ for $12 \mathrm{~h}$. The solutions became clear after approximately $1 \mathrm{~h}$. The products were analyzed by ${ }^{1} \mathrm{H}$ NMR and ${ }^{31} \mathrm{P}$ NMR spectroscopy, as well as by mass spectrometry. Details are given in the Supporting Information. The following amounts of ligand/Pt complex were employed:

Complex 3: Ligand 1 (1.45 mg, $1.16 \mu \mathrm{mol})$ complex (dppe)Pt(OTf) 2 (2.07 mg, $2.32 \mu \mathrm{mol})$.

Complex 4: Ligand $1(1.69 \mathrm{mg}, 1.35 \mu \mathrm{mol})$ and complex (dppp)Pt(OTf) 2 (2.41 mg, $2.71 \mu \mathrm{mol})$.

Complex 5: Ligand 2 (2.01 mg, $1.77 \mu \mathrm{mol})$ and (dppe)Pt(OTf $)_{2}$ (3.16 mg, $3.54 \mu \mathrm{mol})$.

Complex 6: Ligand 2 (1.71 mg, $1.51 \mu \mathrm{mol})$ and complex (dppp)Pt(OTf) $)_{2}(2.73 \mathrm{mg}, 3.01 \mu \mathrm{mol})$.

X-Ray crystallography: CCDC code for complex A (1913332), ligand 1 (1913333), and assembly 4 (1913334) contain the supplementary crystallographic data for this paper. These data can be obtained free of charge from The Cambridge Crystallographic Data Centre via www.ccdc.cam.ac.uk/data request/cif .

Acknowledgements: The work was supported by the Swiss National Science Foundation and by the Ecole Polytechnique Fédérale de Lausanne (EPFL).

Keywords: supramolecular chemistry $\cdot$ metalloligand $\cdot$ platinum complex $\cdot$ coordination cages $\cdot$ prism

[1] N. Fujita, K. Biradha, M. Fujita, S. Sakamoto, K. Yamaguchi, Angew. Chem. Int. Ed. 2001, 40, 1718-1721. 
[2] Y. Yamanoi,Y. Sakamoto, T. Kusukawa, M. Fujita, S. Sakamoto, K. Yamaguchi, J. Am. Chem. Soc. 2001, 123, 980-981.

[3] D. C. Caskey, T. Yamamoto, C. Addicott, R. K: Shoemaker, J. Vacek, A M. Hawkridge, D. C. Muddiman, G. S. Kottas, J. Michel, P. J. Stang, J. Am. Chem. Soc. 2008, 130, 7620-7628.

[4] A. K. Bar, R. Chakrabarty, G. Mostafa, P. S. Mukherjee, Angew. Chem. Int. Ed. 2008, 47, 8455-8459.

[5] A. K. Bar, S. Mohapatra, E. Zangrando, P. S. Mukherjee, Chem. Eur. J. 2012, 18, 9571-9579.

[6] S. Bivaud, J.-Y. Balandier, M. Chas, M. Allain, S. Goeb, M. Sallé, J. Am. Chem. Soc. 2012, 134, 11968-11970.

[7] S. Bivaud, S. Goeb, J.-Y. Balandier, M. Chas, M. Allain, M. Sallé, Eur. J. Inorg. Chem. 2014, 2440-2448.

[8] S. Goeb, S. Bivaud, V. Croué, V. Vajpayee, M. Allain, M. Sallé, Materials 2014, 7, 611-622.

[9] B. Roy, A. K. Ghosh, S. Srivastava, P. D'Silva, P. S. Mukherjee, J. Am Chem. Soc. 2015, 137, 11916-11919.

[10] J. Yang, M. Bhadbhade, W. A. Donald, H. Iranmanesh, E. G. Moore H.Yan, J. E. Beves, Chem. Commun. 2015, 51, 4465-4468.

[11] I. A. Bhat, R. Jain, M. M. Siddiqui, D. K. Saini, P. S. Mukherjee, Inorg Chem. 2017, 56, 5352-5360.

[12] N. Singh, J. Singh, D. Kim, D. H. Kim, E.-H. Kim, M. S. Lah, K.-W. Chi, Inorg. Chem. 2018, 57, 3521-3528.

[13] P. Howlander, B. Mondal, P. C. Purba, E. Zangrando, P. S. Mukherjee J. Am. Chem. Soc. 2018, 140, 7952-7960.

[14] P. Jacopozzi, E. Dalcanale, Angew. Chem. Int. Ed. Engl. 1997, 36, 613615

[15] A. Ikeda, M. Ayabe, S. Shinkai, S. Sakamoto, K. Yamaguchi, Org. Lett 2000, 2, 3707-3710.

[16] F. Fochi, P. Jacopozzi, E. Wegelius, K. Rissanen, P. Cozzini, E. Marastoni, E. Fisicaro, P. Manini, R. Fokkens, E. Dalcanale, J. Am. Chem. Soc. 2001, 123, 7539-7552.

[17] R. Pinalli, V. Cristini, V. Sottili, S. Geremia, M. Campagnolo, A. Caneschi, E. Dalcanale, J. Am. Chem. Soc. 2004, 126, 6516-6517.

[18] S. Bivaud, S. Goeb, V. Crtoué, P. I. Dron, M. Allain, M. Sallé, J. Am Chem. Soc. 2013, 135, 10018-10021.

[19] S. Bivaud, S. Goeb, V. Croué, M. Allain, F. Pop, M. Sallé, Beilstein J. Org. Chem. 2015, 11, 966-971.

[20] V. Croué, S. Goeb, G. Szalóki, M. Allain, M. Sallé, Angew. Chem. Int. Ed. 2016, 55, 1746-1750.

[21] G. Szalóki, V. Croué, M. Allain, S. Goeb, M. Sallé, Chem. Commun 2016, 52, 10012-10015.

[22] S. C. Johannessen, R. G. Brisbois, J. P. Fischer, P. A. Grieco, A. E. Counterman, D. E. Clemmer, J. Am. Chem. Soc. 2001, 123, 3818-3819.

[23] G. Cecot, B. Alameddine, S. Prior, R. De Zorzi, S. Geremia, R. Scopelliti, F. T. Fadaei, E. Solari, K. Severin, Chem. Commun. 2016, 52, 11243 11246.

[24] I. A. Bhat, A. Devaraj, E. Zangrando, P. S. Mukherjee, Chem. Eur. J. 2018, 24, 13938-13946.

[25] G. Cecot, M. Marmier, S. Geremia, R. De Zorzi, A. V. Vologzhanina, P. Pattison, E. Solari, F. Fadaei Tirani, R. Scopelliti, K. Severin, J. Am Chem. Soc. 2017, 139, 8371-8381.

[26] S. M. Jansze, G. Cecot, M. D. Wise, K. O. Zhurov, T. K. Ronson, A. M. Castilla, A. Finelli, P. Pattison, E. Solari, R. Scopelliti, G. E. Zelinskii, A V. Volgzhanina, Y. Z. Voloshin, J. R. Nitschke, K. Severin, J. Am. Chem Soc. 2016, 138, 2046-2054

[27] S. M. Jansze, K. Severin, Acc. Chem. Res. 2018, 51, 2139-2147.

[28] Cage Metal Complexes (Eds.: Y. Voloshin, I. Belaya, R. Krämer), Springer International Publishing AG, Cham, 2017.

[29] R. Thomas, J. P. Nelson, R. T. Pardasani, P. Pardasani, T. Mukherjee, Helv. Chim. Acta 2013, 96, 1740-1749.

[30] C. R. Martinez, B. L. Iverson, Chem. Sci. 2012, 3, 2191-2201.

[31] T. Chen, M. Li, J. Liu, Cryst. Growth Des. 2018, 18, 2765-2783.

[32] Y. Lu, H.-N. Zhang, G.-X. Jin, Acc. Chem. Res. 2018, 51, 2148-2158.

[33] N. Mittal, M. L. Saha, M. Schmittel, Chem. Commun. 2015, 51, 15514 15517.
[34] M. Frank, M. D. Johnstone, G. H. Clever, Chem.Eur. J. 2016, 22, 1410414125.

[35] D. Beaudoin, F. Rominger, M. Mastalerz, Angew. Chem. Int. Ed. 2017, 56, 1244-1248

[36] J. Atcher, J. Bujons, I. Alfonso, Chem. Commun. 2017, 53, 4274-4277.

[37] S. M. Jansze, M. D. Wise, A. V. Vologzhanina, R. Scopolliti, K. Severin Chem. Sci. 2017, 8, 1901-1908.

[38] F. J. Rizzuto, M. Kieffer, J. R. Nitschke, Chem. Sci. 2018, 9, 1925-1930.

[39] C. A. Wiley, L. R. Holloway, T. F. Miller, Y. Lyon, R. R. Julian, R. J. Hooley, Inorg. Chem. 2016, 55, 9805-9815.

[40] Z. Grote, R. Scopelliti, K. Severin, Eur. J. Inorg. Chem. 2007, 694-700.

[41] A. B. Zaitsev, E. Y. Schmidt, A. M. Vasil'tsov, A. I. Mikhaleva, O. V Petrova, A. V. Afonin, N. V. Zorina, Chem. Heterocyclic Comp. 2006, 42 34-41.

[42] P. J. Stang, D. H. Cao, S. Saito, A. M. Arif, J. Am. Chem. Soc. 1995, 117, 6273-6283.

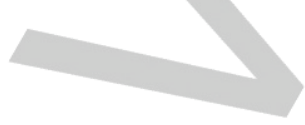




\section{Entry for the Table of Contents}

\section{FULL PAPER}

Metal-ligand assemblies of the general formula $M_{8} L_{4}$ can adopt prismatic or cage-like structures. We show that the self-assembly process can be controlled by using ligands with rigid aromatic side chains.
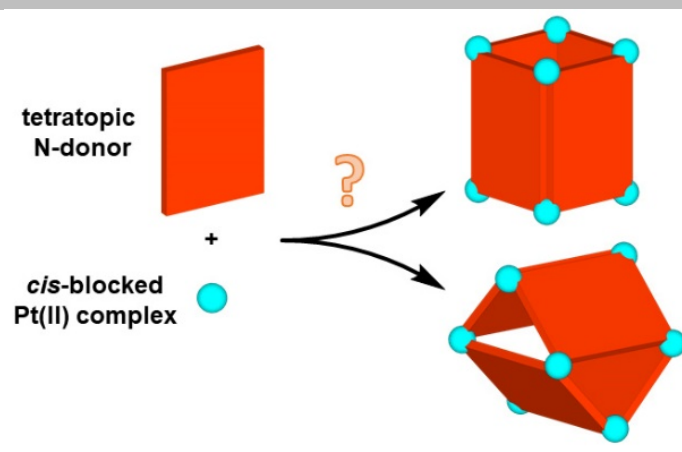

$\mathrm{Pt}$ (II) complex
Metallosupramolecular chemistry

Giacomo Cecot, Martin Tim Doll, Ophélie Marie Planes, Andrea Ramorini, Rosario Scopelliti, Farzaneh Fadaei-Tirani, and Kay Severin*

Page No. - Page No.

Cages versus Prisms: Controlling the Formation of Metallosupramolecular Architectures with Ligand SideChains 